\title{
Phrasal Verbs Revisited: A Probe into Semantics and Functioning of English Phrasal Constructions
}

\author{
Natalia Gvishiani \\ Department of English Linguistics, Faculty of Philology, Lomonosov Moscow State University, Moscow, Russia \\ Email address: \\ ngv@wdcb.ru

\section{To cite this article:} \\ Natalia Gvishiani. Phrasal Verbs Revisited: A Probe into Semantics and Functioning of English Phrasal Constructions. International Journal \\ of Language and Linguistics. Vol. 8, No. 5, 2020, pp. 185-191. doi: 10.11648/j.ij11.20200805.11
}

Received: February 28, 2020; Accepted: September 3, 2020; Published: September 16, 2020

\begin{abstract}
The present study focuses on the distinction between the 'idiom' and the 'open choice' principle in constructing speech with reference to phrasal and semi-phrasal verbs in contemporary English. The semi-compositional reading of some phrasal verbs points to their syntactic, not phraseological nature, and distinguishes them from ready-made idiomatic units. If semi-phrasal verbs get into dictionaries, they are usually listed in the adverb's entry. Compositional phrasal verbs are found to implement semantic patterns with adverbial particles adding pragmatic refinements to the verb's meaning. Being used in variable contexts, semi-phrasal verbs get the 'support' from adverbial particles showing the 'vector' of the action expressed by the verb. The analysis of pragmatic characteristics of phrasal verbs suggests that one of the factors that affect the selection process for the speaker in choosing between a phrasal verb and a monolexemic verb of Romance origin is the functionalstylistic feature of formality / informality. In a preliminary way, variation of choice was considered with reference to translation versions of a literary text. There are indications that monolexemic verbs occur more frequently in the translation version published in the USA. As for lexicographic descriptions and ELT instruction, it is concluded that the adverbial element should be brought more into the limelight as shaping the semantic pattern of the phrasal construction and its functioning in speech.
\end{abstract}

Keywords: Idiomatic / Non-idiomatic Phraseology, Compositional / Semi-compositional Phrasal Verbs, Pragmatic Refinements of Meaning, Semantic / Conceptual Patterns, Variable / Invariable Contexts

\section{Introduction}

It is a widely held view that phraseology covers under its title a large variety of phenomena which, being articulated in form, are perceived as semantically global units. A diversity of language items within its scope share one most salient characteristics: they are distinguished by features of fixedness and idiomaticity they display to a greater or lesser degree. Apart from ready-made units known as 'idioms proper', there are those which without being truly global semantically still remain 'fixed', 'set' or recurrent reflecting typical lexical and semantic choices in constructing speech. Thus, we can speak of idiomatic and non-idiomatic phraseology, the difference between the two being the degree of idiomaticity: some phrases appear to be more literal in meaning than others that involve a semantic transformation or a metaphor. This 'dual' nature of phraseology bringing together fully lexicalized structures and those realizing 'the open choice' principle, has a direct bearing on the study and analysis of English phrasal verbs defined as "a sequence of a lexical element plus one or more particles, e.g. come in, get up, look out for" [1].

The difficulty springs from the fact that the category in question is by no means uniform: there is a wide scatter of structures depending on the type of the adverbial element whether it is phrasal, prepositional, or a general preposition /adverb. Verbal complexes of the kind may present homonymous structures ranging from 'free' verb-adverb combinations through prepositional to idiomatic phrasal verbs with a metaphoric meaning. The more global the meaning of the whole becomes, the looser the link with the adverbial or prepositional element. For example, in "Put the bags on the table", 'on' functions as a general preposition suggesting that the structure can be ranked as a 'free' combination. In "Tremendous pressure was put on the government" or "The more things they put on the menu, the 
tinier amount they give you', 'on' is a phrasal preposition, i.e. an element of a prepositional verb. The same form 'on' is realized as a phrasal adverb within idiomatic phrasal verbs in the following cases: "I've put on an awful lot of weight"; "She is not offended, she is just putting it on" or "He has been arrested and put on trial" [2]. R. A. Close uses semantic criteria to distinguish between phrasal and prepositional verbs and defines the former as idiomatic: "the meaning is never a simple combination of the meaning of the verb and the particle". The term 'prepositional verb' is reserved for verbs of literal meaning ('look at', 'listen to') as distinct from "other verb-plus-preposition combinations of less literal meaning ('come across someone or something'), which are classified as "phrasal verbs"" [3].

Homonymous with phrasal verbs proper are verb-adverb combinations depending on the context that can be used to resolve ambiguity and specify their meaning in discourse. These are non-idiomatic units which are not registered in dictionaries being a realization of 'the open-choice' principle, for example:

"You keep your head under the leaves, and snore away there, till you know no more what's going on in the world, as if you were a bud!"

"Then came another of those melancholy little sighs, and this time the poor Gnat really seemed to have sighed itself away, for, when Alice looked up, there was nothing whatever to be seen on the twig..."

(Lewis Carroll "Alice's Adventures in Wonderland")

No dictionary lists 'snore away' as a ready-made idiomatic verb, which suggests that 'away' functions here as a syntactic and not as a phraseological element used to emphasize continuous action. Although there exists the phrasal verb 'to sigh away', which means 'to sigh continuously', the context helps us to choose the appropriate interpretation of the action that is being described. Most probably, both meanings are realized here: the phrasal one (to waste one's time sighing again and again) and a non-idiomatic 'free' meaning conveyed by the adverb 'away', i.e. "at a distance from someone or something".

It is the verbal combinations of the latter type that are of primary interest to the present investigation. In a way, they shift the focus of analysis in the direction of the adverbial element with its astounding polysemy and polyfunctionality. The broad term 'phrasal verb' may, in fact, embrace cases when the proper and effective use of this type of construction will depend not so much on one's knowledge of the idiomatic meaning of the whole phrase, but on the insights into the sematic and functional potential of the adverbial particle.

\section{Compositional and Non-compositional Phrasal Verbs}

Within the general category of phrasal verbs we can single out non-compositional and compositional ones. The former are idiomatic units which are "learned whole and used whole, and this means that they are not built up from the lexical and grammatical resources of the language each time they are used" [4]. Such items present canonical forms with limited analyzability or variant realizations. The meaning of their components is phrasal - i.e. realized only within a given structure. Non-compositional phrasal verbs are a perfect type of vocabulary items to be included in dictionaries and lexicons. These structures are semantically complete which contributes to their syntactic isolation as phrases. A case in point is 'phrasal-prepositional' verbs, which consist of a verb, a phrasal adverb, and a phrasal preposition, e.g. 'put up with' ("You see what I have to put up with!"), 'get away with' ("I don't know how they managed to get away with paying such low wages"), 'walk out on' ("Her husband walked out on her") [5].

The feature of compositionality is concerned with the connection between discrete words and meanings within a phrase. Some phrasal items allow for compositional reading, while others (idioms proper) do not. Compositionally built up language presupposes "alternating grammatical and lexical elements to express meanings and their relationships to one another" [6]. The meaning of compositional phrasal verbs has semantic and syntactic aspects. We speak of syntactic, not phraseological meaning in this case, which is defined as the functional meaning of a given item determined by the parameters of the situation.

It is not absolutely necessary, therefore, that phrasal verbs should be introduced in speech as recurrent 'ready-made' units which come as a result of 'the idiom principle' and reveal 'the fixedness' of construction. Quite often they turn out to be the outcome of 'the open-choice' principle, which assumes that "words have their own meanings and can be combined according to the rules of grammar and selectional restrictions" [7]. Being semantically 'light' or underspecified, some of the most common English verbs of Anglo-Saxon origin tend to form combinations with other lexical items (adverbial particles included) that make their meaning more precise or differentiated in a given context.

For example, in

"Sue was singing away to herself in the bathroom", "They have been hammering away all day" [LDCE];

"One question nags away: "If art of this quality couldn't save a man's soul, what is it actually for, beyond providing status and a few moments of fleeting pleasure?" (The Daily Telegraph)

'away' in the function of an adverbial particle realizes one of its meanings, i.e. is used to emphasize that the action continues. No wonder that dictionaries do not take into account the verbs 'sing away', 'hammer away', or 'nag away' as idiomatic combinations and do not list them among phrasal verbs. These items appear as speech options hinging on meanings encoded in their components as separate words. Similarly in "The music died away" or "Cut away all the dead wood" [LDCE], 'away' enhances the meaning of completion of the action showing that something disappears or is completely removed.

The above evidence suggests that the adverbs 'away', 'off', 'on', 'in', 'along' and others may express their prototypical 
and figurative meanings in combination with verbs while modifying their semantics in accordance with the context and the speaker's intention. Some such uses get into dictionaries sporadically, but any consistent account is hard to attain since the multiplicity of actual uses is infinite. The lack of differentiation between the open-choice principle and the idiomatic variety seems to be responsible for all the confusion and divergences in how dictionaries and reference books treat the entire subject of phrasal verbs. Adverbial elements in the function of particles cling to the verb semantically and contribute attitudinal, temporal, spatial, or other qualitative characteristics to its 'meaning-in-context'. The whole combination is read semi-compositionally: the meaning is extracted from both words, but the main role of the particle is not its semantic contribution but the intensifying or specifying function in context [8]. On the one hand, compositional items are phrasal in the sense that the resulting meaning seems to be focused on the verb, but, on the other - the way they are constructed in speech, i.e. their structural compositional nature distinguishes them from phrasal verbs proper as fixed 'ready-made' units and suggests the names, such as 'semi- or quasi-phrasal verbs'.

To illustrate the difference between phrasal (noncompositional) and what has been described as semi-phrasal (compositional) verbs, we may consider a number of combinations with the adverbial elements 'away', 'along', and 'off'. Thus, the adverb 'away' is used in its dictionary meaning of emphasizing continuous action in the following cases:

$<$ ICE-GB: S 2A-040 \#40:1: A>:

"In London Ron is surrounded by enthusiastic youngsters including two sons of his own tapping away at Macintosh desktops, while he sits in the corner scribbling away with a fat pen..." (The International Corpus of English - Great Britain - ICE-GB, monologue, unscripted speeches);

$<$ ICE-GB: S 1B-076 \#150:1: A>:

“...but then we're talking about sort of lexicographers toiling away for many many years doing this kind of thing anyway..." (ICE-GB, dialogue public, business transactions) [9].

Lexical items of this kind are rather different from phrasal verbs proper which will be listed in dictionaries as a permanent part of the mental lexicon, e.g.:

"No one insults my family and gets away with it!"; "They criticized the leadership, but shied away from a direct challenge" [LDCE].

The main difference between the two types of combinations (phrasal and semi-phrasal verbs) therefore is the lack of 'fixedness' in the latter unveiling an interesting typological feature of the analytical English structure which consists in supplying modifiers or 'backers up' whenever the word's meaning needs to be defined more precisely or more details should be added. We may quote from John Sinclair in this connection: "The whole drift of the historical development of English has been towards the replacement of words by phrases, with word-order acquiring greater significance" [10]. This tendency is reflected in constructing speech and can naturally be traced back in function-oriented studies which presuppose the use of corpora. Dictionaries, conversely, favour isolated units whose idiomatic meaning needs to be explained.

The adverb 'along' appears to be highly dependent on the verb it modifies. This is probably the reason why the verbal combinations it enters most regularly are given in its dictionary entry, i.e. under the headword 'along' (adverb):

"go / come along: You are welcome to come along if you like; I think I'll go along and watch the game" [LDCE]

"take / bring sb / sth along: Mandy brought some of her friends along; Why don't you take your guitar along? [LDCE]

An interesting point in this connection is that normally verb-adverb combinations are listed in dictionaries under the heading of respective verbs which are most often labelled as 'phrasal verbs'. The difference between the two ways of presenting lexical items is that putting them into the adverb dictionary entry suggests a lesser degree of idiomaticity of the combination, which in this case is presented as a variety of options possible in language use. Parallel to the adverb entry, the same verbal combinations can be included in the dictionary entry under the headword of the given verb suggesting that they have acquired a highly specific meaning within idiomatic units. This may be rather confusing because 'go / come along' and 'take / bring somebody / something along' in the above sentences, for example, are quite different from truly idiomatic units, in which case the idiomaticmetaphoric meaning is obviously there: "They get along well" (have a friendly relationship) or "After a five hour operation, Wendy is coming along just fine" (improving, developing, making progress) [LDCE].

Using semi-phrasal compositional verbs, however, requires the knowledge of literal and metaphoric meanings of respective adverbial elements. The majority of such expressions are not registered in dictionaries, neither they should be since they appear as selectional options in constructing speech.

The adverb 'off' regularly enters into a variety of verbal combinations, both phrasal and 'semi-phrasal' ones. Its frequency in the corpus [ICE-GB] is much higher than that of the adverbs 'away' and 'along' discussed above. This suggests that as a speech option it features most prominently in present-day English:

"By now my half-awake and sulky men were clattering into shape on the road. Soon Hooper's platoon had marched off into the darkness";

"I handled stores with them for the first half hour; then broke off to meet the company second-in-command who came down with the first returning truck";

"'B' Company relieved us. I've sent the chaps off to get cleaned up".

(Evelyn Waugh "Brideshead Revisited")

Although 'send off' is marked in the dictionary as a phrasal verb especially when realizing the meaning 'to send something by post', it seems that in the two cases above (including 'marched off'), the adverb carries its general meaning "away from a place" while contributing to the 
meanings that are already present in the verbs. Most idiomatic of all is the phrasal verb 'break off' clearly demonstrating fixedness of expression which becomes ambiguous or downright meaningless if the adverbial element is removed.

\section{Semi-phrasal Verbs: Pragmatic Refinements of Meaning}

The compositional nature of semi-phrasal verbs suggests that both elements of a 'verb + particle' combination contribute to its meaning. According to G. Nunberg [11], compositionality is "the degree to which the meaning of a construction can be analyzed in terms of the contributions of its constituent parts". Moreover the existing constructions may form a semantic pattern according to which new combinations can be formed [12]. Thus, the compositional verbs sing away, hammer away, toil away, chat away and others present a pattern of using the adverbial particle away in a specifying function, which in this case can be defined as emphasizing continuous action. The combinations fade away, melt away, slip away or cut away reveal another semantic pattern realized by the element away, i.e. the pragmatic refinement of completion of the action.

Similarly the adverbial particle out adds the meaning of completion to the verbs it is combined with: to clear out, to copy out, to tire out. And the particle off expresses the meaning of finding something at a distance or suggests the presence of barriers: keep off, hold off. It also occurs in contexts showing the meaning of removal or exemption. The semantic pattern realized by the adverbial element in such cases is to indicate the vector of action.

If the adverbial component of a semi-phrasal verb is removed, the meaning of the whole will be less complete; the character of the action, however, will be preserved [13]. Thus, compositional verbs present 'variable contexts' as distinct from 'invariable contexts' of non-compositional ones. Units of 'variable contexts' are situational combinations in discourse realizing a given semantic pattern. Units of 'invariable contexts' (non-compositional phrasal verbs) belong to the phraseological thesaurus of the language and serve as an object of idiomatic phraseology.

In units of 'variable context', the verb does not change its lexical meaning, and the adverbial particle only contributes various pragmatic refinements: to sing - to sing away, to chat - to chat away. Units of 'constant context' have a holistic meaning, i.e. the meanings of the verb and the adverbial particle are "in a weak state": to get away with, to put up with [14]. The configuration of contextual features can tell us a lot about how the action is perceived. The selection of objects in the event, i.e. its propositional interpretation determines how the verb is correlated with the event and what 'vector' or pragmatic refinement is required. Single structures may present phenomena of different contextual order, with adverbial elements realizing meanings related to the verb or a given speech situation.
Spatial refinements of the verb's meaning may follow the pattern indicating aspectual characteristics, such as turning non-terminative verbs into terminative ones: to stand - to stand up, to speak - to speak out [15]. The meaning of verbs of 'dual' aspectual nature depends on the context, and the adverbial particle can show how the action expressed by the verb relates to the speech event. For example, the terminative element can be eliminated by using the adverbial particle away (to write - to write away) or, conversely, the idea of termination of action made obvious (to cry - to cry out, to eat - to eat up). In terminative verbs, the regular pattern for adverbial particles is to express completeness of action (to hush up, to lay down, to fix up). In non-terminative ones they obtain the meaning of duration and intensity (to laugh away, to smoke away, to talk away).

As can be seen, meanings of semi-phrasal combinations emerge from their implementation in the given context. Such combinations preserve the lexical meaning of the verb and the semantic functional load of the adverbial particle. The variable character of lexical and syntactic contexts can be verified by applying the substitution test in the analysis of phrasal constructions. Semi-phrasal combinations do not realize a fixed ultimate context since different adverbial particles can add similar specification refinements to the verb's meaning and different verbs can obtain the same pragmatic feature from a given adverbial particle. Adverbial particles, therefore, are a special kind of 'form words': they follow a functional-semantic pattern in contextual use and contribute aspectual as well as 'qualitative' characteristics to the verb - those of directionality, completeness, and intensity.

In terms of cognitive analysis, the process of conceptualization reveals the 'convoluted' nature of phrasal verbs, when the adverbial element ('a satellite') indicates a vector of the action denoted by the verb [16]. According to Lucien Tesnière, "the verbal node is the core of a little drama that involves actors, circumstances and a process" [17].

\section{Phrasal Verbs vs. Monolexemic Verbs of Romance origin: Distribution in Discourse}

Phrasal verbs are known to be stylistically differentiated according to the register of discourse. They are generally viewed as characteristically less formal than their monolexemic synonyms of Romance origin. For example, make out / complete (When you make out / complete the bill, please give me a copy); taken up / deceived (Were you really taken up / deceived by an old trick like that?); went on / continued (The chairman went on / continued to give details of the meeting). Being more 'user-friendly' pragmatically, phrasal verbs are often a priority in conversation or informal discussion. Stylistically neutral phrasal verbs regularly occur in academic discourse where their meaning gets narrowed down and specialized: sum up, give up, point out, work out, come about, call for, bring out, try out, set about, etc.

Still with regard to the speaker's choice, we may wonder 
what affects the selection process when both options are available, i.e. an idiomatic way of expressing a thought by means of a phrasal verb and a more descriptive speech token (a monolexemic Romance verb). In the first place, we come across such parallels in dictionaries, where monolexemic verbs may figure in definitions of phrasal verbs and vice versa: set up (a company or organization) / establish ("They want to set up their own import-export business"); find out / discover ("to get information after trying to discover it or by chance") [LDCE]. While considering dictionary definitions, we may see the difference between the compared items: the phrasal verbs set up and find out turn out to be broader in their semantic scope and more polyfunctional as compared with the monolexemic verbs establish and discover which belong to the academic register.

Judging by the dictionary evidence, it is hard to define criteria for establishing a choice between phrasal and monolexemic verbs as they become subject to pragmatic and collocation-bound restrictions in actual use. There is one type of context, however, when some preferences can be revealed with regard to their distribution in discourse. A case in point

Type 1 (the translation version published in Britain)

"Five minutes later the express train disappeared from under the glass vault of the train station and vanished clean away in the darkness. And with it vanished Rimsky."

"But as soon as the conductress yanked the cord and the "But no sooner did the conductress pull the cord and the tram-car started moving off, the cat acted like anyone whostreetcar start to move, than the cat did just what anyone who has been expelled from a tram-car but sail needs a ride."

has been kicked off a streetcar and still has somewhere to go would do."

"And Grunya is not here, I sent her off to Voronezh. She "And Grunya isn't here, I sent her to Voronezh. She was complained you diddled her out of a vacation."

It can be assumed that here we deal with semicompositional verbs, where the adverbial element is an option, but not an obligatory constituent of the wordcombination. The phrase remains fully meaningful when the

\section{Translation version 1}

"However, we're talking away, my dear Fagott, and the audience is beginning to get bored. My gentle Fagott, show usaudience is beginning to get bored. Show us something simple some simple little thing to start with."

Secondly, we can observe a frequent use of monolexemic verbs of Romance origin in the translation version 2

Translation version 1

"Exactly a minute later a pistol shot rang out, the mirrors "Exactly a minute later a shot rang out, the mirrors disappeared, the display windows and stools dropped away,disappeared, the display cases and stools vanished, and the the carpet melted into air, as did the curtain."

"I got so carried away reading the article about myself that "I was so absorbed in reading about myself that I didn't I didn't notice (I had forgotten to lock the door) how she cameeven notice her standing in front of me (I'd forgotten to shut in and stood before me with a wet umbrella in her hand andthe door), holding a wet umbrella and wet newspapers." wet newspapers as well."

"As the steps died away, Annushka slipped like a snake "Hearing the footsteps fade, Annushka slithered out from from behind the door, put the can down by the wall, droppedbehind the door like a snake, stood her oil can against the to the floor on her stomach, and began feeling around." carpet melted into thin air along with the curtain."

adverbial component is removed. Interestingly, some forms clearly show the traces of American English in the translation version 2 [18]:

Translation version 2

for starters."

(published in the USA) as compared with translation version 1 (published in Britain):

Translation version 2 wall, lay down on her stomach and started feeling around on the floor of the landing. " 
"Pilate drove this thought away, and it flew off as instantly as it had come flying."

"They say he has become taciturn and keeps away from women."

"He was carried along now, smothered and burned, by the most terrible wrath - the wrath of impotence."

Although we are far from assuming that the above evidence may lead to full-proof conclusions concerning the difference between British and American usage as far as

Translation version 1

"You've upset me, Nikanor Ivanovich, and I was counting on you. So, our number didn't come off."

As some recent findings indicate, "American phrasal verbs are 'young': $90 \%$ of phrasal verbs are neologisms which entered the language over the last 20-30 years" [19].

\section{Conclusion: Implications for Linguodidactics}

Phrasal verbs present a challenge for linguists and language learners because of their polysemy, polyfunctionality, and, last but not least, what has been described as their 'convoluted' semantic content. In dealing with phrasal verbs, 'the idiom' and 'the open choice' principles in constructing speech should be kept clearly apart. Non-compositional phrasal verbs belong to the idiomatic variety as part of the speaker's mental lexicon. What should be brought more into the limelight in lexicographic descriptions and ELT instruction are compositional (semi-phrasal verbs), which are formed according to semantic patterns. Adverbial particles then occur in variable contexts and add pragmatic refinements to the verb's meaning, which include continuous action, completion of the action, terminative or perfective meaning, a stronger dynamic component and others. In the case of semi-phrasal verbs, the adverbial element is brought into prominence as realizing its literal or figurative meaning: it plays a significant role in forming a verbal combination and shaping the semantic pattern of its functioning in speech.

Hence we can speak of two cognitive strategies in forming / using 'verb + particle' combinations - the idiomatic and compositional ones. If the former draws on 'fixed' readymade units, the latter - implements various conceptual patterns. Most such expressions are not registered in dictionaries, neither they should be since they realize a compositional conceptual pattern. The compositional strategy, being naturally more comprehensible to native speakers of the language, needs to be given more space in $\mathrm{L} 2$ teaching as it focuses on the functional potential of adverbial particles in forming phrasal constructions. The relevance and actuality of this approach is vindicated by ample evidence of current publications highlighting the fact that international students either 'shy away' from phrasal verbs or do not use them enough $[20,21$. 22]. To conquer such hazards and
"Pilate dismissed that thought, and it flew away as fast as it had flown in."

"They say that he has become taciturn and avoids women."

"Now he was engulfed by the most terrible rage of all, rage that choked and burned him-the rage of powerlessness."

phrasal verbs are concerned, it looks suggestive of the fact that informal phrasal verbs occur more frequently in the British variety:

Translation version 2

"You're a disappointment to me, Nikanor Ivanovich! I had such faith in you. So then, this particular act has not been a success."

uncertainty, the present article proposes a new slant in treating phrasal verbs - i. e. more emphasis on the metaphoric potential of adverbs and the distinction between phrasal and 'semi-phrasal' constructions.

In pragmatics, we deal with dynamic meanings of phrasal verbs and their contextual correspondences, which can be derived from the speech event provided that they produce the same effect as the source meanings do. A contrastive analysis of translation versions of the same original text proved to be instrumental in demonstrating a variety of options for the speaker ranging from phrasal compositions to stylistically more formal monolexemic units.

\section{References}

[1] D. Crystal, A Dictionary of Linguistics and Phonetics. Oxford, 1985, p. 232.

[2] N. Gvishiani, An Introduction to Contrastive Lexicology. Moscow, 2010, p. 106.

[3] R. A. Close, A Reference Grammar for Students of English. London: Longman, 1975, p. 27.

[4] G. Philip, Colouring Meaning. Collocation and Connotation in Figurative Language. Amsterdam / Philadelphia: John Benjamins Publishing Company, 2011, p. 17.

[5] Longman Dictionary of Contemporary English (LDCE). Third edition, Longman, UK, 1995.

[6] G. Philip, Colouring Meaning. Collocation and Connotation // Figurative Language. Amsterdam / Philadelphia: John Benjamins Publishing Company, 2011, p. 15.

[7] O. Mudraya, S. Piao, P. Rayson, S. Sharoff, B. Babich, and L. Löfberg, "Automatic extraction of translation equivalents of phrasal and light verbs in English and Russian" in Phraseology: an Interdisciplinary Perspective. Edited by S. Granger and F. Meunier. Amsterdam: John Benjamins, 2009, p. 293.

[8] G. Philip, Colouring Meaning. Collocation and Connotation in Figurative Language. Amsterdam / Philadelphia: John Benjamins Publishing Company, 2011, p. 85.

[9] The International Corpus of English - Great Britain (ICE-GB) https://www.ucl.ac.uk/english-usage/projects/ice-gb/. 
[10] J. Sinclair, Corpus Concordance Collocation. Oxford University Press, 1991, p. 67.

[11] G. Nunberg, I. Sag, T. Wasow, Idioms // Language, 70 (3), 1994, pp. 491-538.

[12] P. Ronan, G. Schneider, Determining light verbs constructions in contemporary British and Irish English // International Journal of Corpus Linguistics, 2015, 20 (3), pp. 326-354.

[13] D. Spasov, English Phrasal Verbs. Sofia, 1966, p. 12.

[14] A. I. Smirnitskij, English Lexicology. Moscow, 1956, p. 212.

[15] N. N. Amosova, Osnovy anglijskoj fraseologii. Moscow: URSS, 2010: p. 131.

[16] L. Talmy, Path to Realization: A typology of event conflation // Procedings of the 17th Annual Meeting of the Berkeley Linguistics Society. Berkeley, Calif. Berkeley Linguistics Society, 1991, p. 480.

[17] L. Tesnière, Elements of Structural Syntax. Paris: Klincksieck, 1959 , p. 73.

[18] O. Rozumnaja, A comparative analysis of semantics and functioning of phrasal verbs in the British and American varieties of the English language (based on the data of the British National Corpus and The Corpus of Contemporary American English). Graduation paper, Lomonosov Moscow State University, Moscow, 2019, pp. 87-104.

[19] E. Golubkova, O. Medvedeva, A Typology of Phrasal Verbs Distinctions in British and American English (a corpus-based analysis). // Vestnik Moskovskogo Gosudarstvennogo Lingvistitseskogo Universiteta, Moscow, 2012, p. 60.

[20] R. Spring, Teaching Phrasal Verbs More Efficiently: Using Corpus Studies and Cognitive Linguistics to Create a Particle List. // Advances in Language and Literary Studies, 2018, 9 (5), pp. 121-135.

[21] Tran Phan Ngoc Tu, Tran Quoc Thao, The Use of Phrasal Verbs in English Language Research Proposals by Vietnamese M. A. Students. // VNU Journal of Foreign Studies, Vol. 35, No 4, 2019, pp. 114-129.

[22] M. Alangari, S. Jaworska, J. Laws, Who's Afraid of Phrasal Verbs? The Use of Phrasal Verbs in Expert Academic Writing in the Discipline of Linguistics, // Journal of English for Academic Purposes, Vol. 43, 2020, pp. 2-13. 